\title{
Analytical validation of a quantitative method for therapeutic drug monitoring on the Alinity ${ }^{\circledR} \mathrm{c}$ Abbott
}

\author{
Validation analytique d'une méthode de dosage adaptée \\ au suivi thérapeutique pharmacologique sur l'Alinity ${ }^{\circledR} \mathrm{c}$ Abbott
}

\author{
Nathalie Dubois \\ Ghali Sqalli \\ Maud Gilson \\ Corinne Charlier \\ Toxicology Department, \\ University Hospital, Liege, Belgium
}

\begin{abstract}
Objective: The aim of this study was to evaluate the analytical performance of the Alinity ${ }^{\circledR} \mathrm{c}$ Abbott compared to the Architect ${ }^{\circledR}$ immunoassay system for the determination of drugs having a narrow therapeutic index. Methods: Valproic acid, amikacin, gentamicin, phenobarbital and vancomycin were analyzed using Particle-Enhanced Turbidimetric Inhibitor Immunoassay (Petinia), phenytoin and theophylline were analyzed using an immunoenzymatic method and a colorimetric method was performed to quantify lithium. The methods were validated according to the total error approach. Seven validation standards were analyzed in quintuplet during four days to establish the limits of the methods. Dilution integrity and interferences (hemolysis and high concentrations of bilirubin and lipids) were also tested. Depending on the analyte, the results obtained for twenty to forty patients on the Alinity ${ }^{\circledR}$ were compared to those obtained on the Architect ${ }^{\circledR}$. Results: The bias and the coefficients of variation for repeatability and for intermediate precision were lower than $15 \%$ for all drugs. Accuracy profiles were acceptable (acceptance limits fixed at 30\%) in the validated ranges. The lower limits of quantification (LLOQ) were similar to those determined by Abbott except for gentamicin for which we determined a LLOQ at $1.22 \mathrm{mg} / \mathrm{L}$ while Abbott determined it at 0.5 $\mathrm{mg} / \mathrm{L}$. All assays diluted linear and analyte concentrations were not affected by interferences. Concentrations obtained for real samples on the Alinity ${ }^{\circledR} \mathrm{c}$ are comparable to those obtained on the Architect ${ }^{\circledR}$ ci. Conclusions: The analytical validation of a method suitable for therapeutic drug monitoring of drugs on the Alinity ${ }^{\circledR} \mathrm{c}$ meets the requirements of European Medicines Agency.
\end{abstract}

Key words: therapeutic drug monitoring, Petinia (Particle enhanced turbidimetric inhibition immunoassay), Alinity, plasma

Résumé. Objectif : L'objectif de cette étude est d'évaluer les performances analytiques d'une méthode adaptée au suivi thérapeutique pharmacologique de médicaments ayant un intervalle thérapeutique étroit sur l'Alinity ${ }^{\circledR} \mathrm{c}$ Abbott et de les comparer à celles de l'Architect ${ }^{\circledR}$ Abbott. Méthode : L'acide valproïque, l'amikacine, la gentamicine, le phénorbarbital et la vancomycine sont analysés grâce à la méthode Petinia (Particle-enhanced turbidimetric inhibitor immunoassay) ; la phénytoïne et la théophylline grâce à une méthode immunoenzymatique et le lithium grâce à une méthode colorimétrique. Sept standards de validation ont été analysés en quintuple pendant 4 jours pour établir les limites de la méthode selon le principe de l'erreur totale. L'intégrité des dilutions et l'influence d'interférences (hémolyse et concentrations élevées de bilirubine et de lipides) ont également été vérifiées. Les résultats obtenus pour 20 à 40 échantillons de patients réels sur l'Alinity ${ }^{\circledR}$ ont été comparés aux résultats obtenus sur l'Architect ${ }^{\circledR}$. Résultats : Les biais relatifs et les coefficients de variation sont inférieurs à $15 \%$. Les profils d'exactitude sont acceptables (valeurs d'acceptation fixées à $30 \%$ ). Les limites de quantification inférieures 
(LLOQ) sont similaires à celles déterminées par Abbott sauf pour la gentamicine où nous avons déterminé une LLOQ à $1,22 \mathrm{mg} / \mathrm{L}$ tandis qu'Abbott l'avait évaluée à $0,5 \mathrm{mg} / \mathrm{L}$. Les performances des méthodes ne sont affectées ni par les dilutions ni par les interférences. Les concentrations obtenues pour des échantillons réels sur Alinity ${ }^{\circledR}$ sont comparables à celles obtenues sur Architect ${ }^{\circledR}$. Conclusion : La validation analytique d'une méthode de dosage permettant le suivi thérapeutique de 8 médicaments sur Alinity ${ }^{\circledR} \mathrm{c}$ répond aux exigences de l'Agence européenne des médicaments.

Mots clés: suivi thérapeutique pharmacologique, Petinia (Particle enhanced turbidimetric inhibition immunoassay), Alinity, plasma

In clinical practice, therapeutic drug monitoring is used mainly for monitoring specific drugs with narrow therapeutic index. The main aims of therapeutic drug monitoring are to avoid therapeutic failures due to bad compliance or inadequate dose of medication, as well as adverse or toxic effects due to an excessive dose [1-4].

Therapeutic drug monitoring is important to check that drug concentrations found in patient blood are sufficient to ensure treatment efficacy. Moreover, the eight drugs studied in this work have a narrow therapeutic index which can lead to serious therapeutic failures or adverse effect reactions. Amikacin and gentamicin are antibacterial drugs that are part of the aminoglycoside family; they are mostly used in hospital to treat serious infections. Therapeutic drug monitoring of aminoglycosides is essential because of their potential ototoxicity and nephrotoxicity [5]. Vancomycin is an antibiotic also used for the treatment of serious infections which can cause serious life-threatening side effects [6]. Theophylline is a bronchodilator used to treat asthma symptoms for which overdose can occur rapidly [7]. Valproic acid, phenytoine and phenobarbital are essentially used as anticonvulsant drugs [8]. They can lead to severe liver disease and to other severe adverse effects. Lithium is used to treat manic episodes related to bipolar disorder. Therapeutic drug monitoring of lithium is very important since large interindividual variability was found for lithium pharmacokinetics [9].

The aim of this study is to evaluate the analytical performance of particle enhanced turbidimetric inhibition immunoassay (Petinia) used for the quantitative determination of eight drugs on the Alinity ${ }^{\circledR} \mathrm{c}$ (Abbott) and compare it to the chemiluminescence microparticle immunoassay (CMIA) method automated on the Architect ${ }^{\circledR}$ immunoassay system.

\section{Materials and methods}

\section{Instrumentation}

All assays were performed on the Alinity ${ }^{\circledR} \mathrm{c}$ from Abbott Laboratories (Hennigsdorf, Germany). Valproic acid, amikacin, gentamicin, phenobarbital and vancomycin were analyzed using Particle-enhanced turbidimetric inhibitor immunoassay (Petinia), phenytoin and theophylline were analyzed using an immunoenzymatic method and a colorimetric method was performed to quantify lithium.

\section{Reagents}

Reagent kits for Alinity ${ }^{\circledR} \mathrm{c}$ were provided by Abbott. The six levels of calibration standards for valproic acid, amikacin, gentamicin, phenobarbital, phenytoin, theophylline and vancomycin were part of the TDM multiconstituent calibrator kit supplied by Abbott. They were standardized by gravimetric method. The one-level calibrator for lithium was the clinical chemistry calibrator commercialized by Abbott. QC Multichem ${ }^{\circledR}$ S Plus Assayed was manufactured by Technopath (Tipperary, Ireland), it is a serum chemistry and immunology internal quality control that mimics patient samples and is targeted at key clinical decision point.

\section{Method validation}

The analytical method validation was performed according to the Guideline on bioanalytical method validation from the European medicines agency [10] and the guidelines of the French society of pharmaceutical sciences and techniques (SFSTP) [11-14].

The validation standards were analyzed in quintuplet during four days. They were covering the calibration curve range: the lower limit of quantification (LLOQ), three times the LLOQ, around 30 to $50 \%$ of the dosing range and at least $75 \%$ of the upper calibration curve range.

Three levels of internal QC Multichem ${ }^{\circledR}$ S Plus Assayed were used as validation standards, additional four levels were made by spiking heparinized plasma with known amounts of drug solutions. Stock solution of valproic acid was prepared from valproate for injection/perfusion 300 $\mathrm{mg} / 3 \mathrm{~mL}$ (Mylan, Hoeilaart, Belgium), amikacin from Amukin ${ }^{\circledR}$ for injection/perfusion $500 \mathrm{mg} / 2 \mathrm{~mL}$ (BristolMyers Squibb, Braine l'Alleud, Belgium), gentamicin from gentamycine for perfusion $80 \mathrm{mg} / \mathrm{mL}$ (B. Braun, Melsun- 
Table 1. Target concentrations of the standards of validation.

\begin{tabular}{|lllllllll|}
\hline \multirow{2}{*}{ Level } & $\mathbf{V A L}$ & $\mathbf{A M}$ & $\mathbf{G E}$ & $\mathbf{L I T}$ & $\mathbf{P H L}$ & $\mathbf{P H O}$ & THE & $\mathbf{V A}$ \\
& $\mathbf{m g} / \mathbf{L}$ & $\mathbf{m g} / \mathbf{L}$ & $\mathbf{m g} / \mathbf{L}$ & $\mathbf{m m o l} / \mathbf{L}$ & $\mathbf{m g} / \mathbf{L}$ & $\mathbf{m g} / \mathbf{L}$ & $\mathbf{m g} / \mathbf{L}$ & $\mathbf{m g} / \mathbf{L}$ \\
\hline 1 & 12.5 & 2.30 & 0.500 & 0.101 & 2.00 & 1.80 & 2.00 & 1.40 \\
\hline 2 & 32.6 & 5.12 & 1.35 & 0.303 & 6.00 & 5.40 & 6.00 & 4.20 \\
\hline 3 & 37.5 & 6.90 & 1.50 & 0.618 & 14.9 & 7.42 & 6.47 & 5.32 \\
\hline 4 & 57.2 & 11.7 & 4.78 & 1.40 & 30.5 & 13.6 & 14.9 & 21.0 \\
\hline 5 & 75.0 & 25.0 & 5.00 & 1.76 & - & 20.0 & 20.0 & 35.8 \\
\hline 6 & 87.9 & 29.3 & 7.50 & 1.89 & 52.3 & 22.7 & 23.5 & 50.0 \\
\hline 7 & 113 & 37.5 & 7.66 & 2.63 & 60.0 & 30.0 & 30.0 & 75.0 \\
\hline
\end{tabular}

NB: values in italic are the target concentrations for internal QC Multichem S Plus, other values are the target concentrations for spiked samples; VAL: valproic acid, AM: amikacin, GE: gentamicin, LIT: lithium, PHL: phenobarbital, PHO: phenytoin, THE: theophylline, VA: vancomycin.

gen, Germany), lithium from a Certi Pur solution 1000 mg/L (VWR Int., Oud-Heverlee, Belgium), phenobarbital from phenobarbital for injection $200 \mathrm{mg} / 2 \mathrm{~mL}$ (Sterop, Anderlecht, Belgium), phenytoin from Diphantoine ${ }^{\circledR}$ for injection $250 \mathrm{mg} / 5 \mathrm{~mL}$ (Kela Pharma, Saint-Nicolas, Belgium), theophylline from Theospirex ${ }^{\circledR}$ ampoule $200 \mathrm{mg} / 10$ $\mathrm{mL}$ (Gebro Pharma, Liestal, Switzerland) and vancomycin from vancomycine for injection $200 \mathrm{mg} / 10 \mathrm{~mL}$ (Mylan, Hoeilaart, Belgium). The preparation of the validation standards for immunoassay analytical validation is sometimes challenging because the use of methanolic solutions to spike plasma can modify the biological matrix, even after addition of low volume, and introduce a bias in the trueness determination; that is the reason why we chose the use of drug solutions used for perfusion and/or injection to fortify plasma. Commercial internal QC Multichem ${ }^{\circledR}$ S Plus Assayed will be used daily in the laboratory when the eight drug tests will be performed routinely. The use of those internal quality controls as validation standards is helpful to determine in advance the coefficients of variation for intermediate precision that will be applied for daily routine. The validation standards were used to estimate the trueness, the repeatability, the intermediate precision, the uncertainty of measurement, the accuracy, the linearity and the lower limit of quantification (LLOQ) of the method. The e-noval software V4.1 (Pharmalex, Mont Saint-Guibert, Belgium) was used to compute all validation results and to build the accuracy profiles. The concentrations of the validation standards for all analytes are presented in table 1.

The dilution integrity was controlled by spiking heparinized plasma with stock solutions to obtain a concentration greater than the upper limit of quantification (ULOQ) and by diluting them two times in the blank matrix for all analytes and five times for amikacin and gentamicin.

Three interferences (hemolysis and abnormal concentrations of bilirubin and lipids) were tested for each analyte at two concentration levels (levels 1 and 3 of internal Multichem ${ }^{\circledR}$ S Plus Assayed (Technopath)) according to
Clinical and Laboratory Standards Institute [15]. To test hemolysis influence, red blood cells were collected from heparinized blood after centrifugation and plasma removal. They were washed three times with cold physiological fluid and lysed by the addition of the same volume of desionised water. This mixture was then centrifuged to discard cell debris. Hemolysate hemoglobin was measured on Sysmex ${ }^{\circledR}$ x 5800i (Sysmex, Hoeilaart, Belgium). For abnormal bilirubin concentration influence testing, $90 \mathrm{mg}$ of bilirubin (Sigma Aldrich, Machelen, Belgium) were dissolved in $7.5 \mathrm{~mL}$ of $\mathrm{NaOH} 0.1 \mathrm{M}$, and then 22.5 $\mathrm{mL}$ of deionized water were added. For abnormal lipid concentration influence analysis, a solution of intralipid $20 \%$ was prepared. The triglyceride concentration of that solution was measured on Cobas ${ }^{\circledR}$ (Roche Diagnostics, Vilvoorde, Belgium). Each "interfering solution" was diluted in water to obtain $25 \%, 50 \%$ and $75 \%$ concentrations. Then, $30 \mu \mathrm{L}$ of "interfering solutions" and $25 \%, 50 \%$, $75 \%$ and $100 \%$ were added to $270 \mu \mathrm{L}$ of internal QC. The obtained results were compared in terms of relative bias to the concentration obtained for a control sample which consisted in $270 \mu \mathrm{L}$ of internal QC to which $30 \mu \mathrm{L}$ of water were added. Each sample was analyzed in triplicate.

Finally, the results obtained for twenty to forty patients depending on the analyte were compared to those obtained by the method (Architect ${ }^{\circledR} \mathrm{ci}$, Abbott Laboratories) previously used by a linear regression and by a Bland and Altman plot. The concordance assessment by Bland-Altman consists in a plot showing on $y$-axis the difference values obtained by the two analytical techniques and on $\mathrm{x}$-axis the mean values obtained by these two techniques. The bias between the two methods is estimated by the mean of the difference values. The standard deviation (SD) is calculated from these difference values to estimate the random fluctuations around this mean. It is common to compute $95 \%$ limits of agreement for each comparison (mean difference $\pm 1.96 \mathrm{SD}$ of the difference) [16]. 
Table 2. Trueness expressed as relative bias (\%), intra-assay (repeatability) and inter-assay precision (intermediate precision) expressed as coefficient of variation (\%), uncertainty of measurement expressed as relative expended uncertainty (\%), lower and upper limits of quantification.

\begin{tabular}{|c|c|c|c|c|c|c|c|c|c|}
\hline & Level & VAL & AM & GE & LIT & PHL & PHO & THE & VA \\
\hline \multirow{7}{*}{$\begin{array}{l}\text { Trueness } \\
\text { Relative bias (\%) }\end{array}$} & 1 & -0.520 & 10.6 & 10.3 & -2.48 & 10.9 & -5.69 & -9.93 & 8.00 \\
\hline & $\underline{2}$ & -15.2 & -2.92 & 6.26 & 1.98 & -10.9 & 6.82 & -10.4 & 7.64 \\
\hline & 3 & 3.51 & 12.5 & 16.1 & 1.38 & 6.14 & 2.07 & -5.77 & 0.320 \\
\hline & 4 & -4.64 & -1.54 & 1.42 & 4.86 & -1.07 & 2.61 & -8.26 & -1.21 \\
\hline & 5 & 2.65 & 11.3 & 12.5 & -0.741 & - & 5.38 & -9.75 & -1.51 \\
\hline & 6 & -0.199 & 0.785 & 10.0 & 5.42 & -6.12 & 1.92 & -0.851 & -2.50 \\
\hline & 7 & 6.13 & 12.6 & -3.35 & -3.25 & -8.41 & 6.47 & -7.13 & -6.23 \\
\hline \multirow{7}{*}{$\begin{array}{l}\text { Intra-assay precision } \\
\text { Repeatability (CV\%) }\end{array}$} & 1 & 3.51 & 6.33 & 8.70 & 8.13 & 5.48 & 4.01 & 2.41 & 5.57 \\
\hline & 2 & 0.964 & 2.17 & 1.27 & 2.02 & 2.36 & 2.88 & 2.19 & 1.69 \\
\hline & 3 & 0.778 & 2.85 & 1.03 & 1.70 & 1.65 & 2.94 & 1.31 & 1.28 \\
\hline & 4 & 0.546 & 2.07 & 0.487 & 0.598 & 1.88 & 3.51 & 1.53 & 0.412 \\
\hline & 5 & 1.04 & 1.23 & 1.27 & 0.806 & - & 1.97 & 2.03 & 1.32 \\
\hline & 6 & 0.594 & 2.08 & 2.95 & 0.664 & 2.41 & 3.03 & 1.90 & 1.02 \\
\hline & 7 & 1.64 & 1.79 & 1.55 & 0.964 & 2.37 & 2.40 & 4.61 & 2.28 \\
\hline \multirow{7}{*}{$\begin{array}{l}\text { Inter-assay precision } \\
\text { Intermediate precision (CV\%) }\end{array}$} & 1 & 6.87 & 7.71 & 39.4 & 12.4 & 6.15 & 7.72 & 4.65 & 10.7 \\
\hline & 2 & 6.47 & 2.61 & 4.36 & 2.74 & 2.57 & 5.07 & 2.88 & 4.51 \\
\hline & 3 & 2.68 & 3.25 & 3.31 & 2.51 & 4.01 & 3.46 & 4.74 & 3.28 \\
\hline & 4 & 5.39 & 2.07 & 1.60 & 1.63 & 3.72 & 4.67 & 4.84 & 0.796 \\
\hline & 5 & 2.73 & 1.84 & 2.07 & 1.80 & - & 2.36 & 2.83 & 1.37 \\
\hline & 6 & 3.28 & 2.08 & 3.43 & 1.73 & 2.99 & 4.25 & 6.24 & 2.21 \\
\hline & 7 & 1.64 & 2.77 & 1.56 & 1.06 & 3.47 & 2.40 & 5.90 & 2.28 \\
\hline \multirow{7}{*}{$\begin{array}{l}\text { Uncertainty of measurement } \\
\text { Relative expended uncertainty (\%) }\end{array}$} & 1 & 15.1 & 16.3 & 87.8 & 27.0 & 12.9 & 16.9 & 10.2 & 23.35 \\
\hline & 2 & 14.4 & 5.51 & 9.68 & 5.84 & 5.35 & 11.0 & 6.14 & 9.96 \\
\hline & 3 & 5.95 & 6.80 & 7.34 & 5.41 & 8.85 & 7.27 & 10.5 & 7.24 \\
\hline & 4 & 12.0 & 4.24 & 3.54 & 3.61 & 8.14 & 9.97 & 10.8 & 1.74 \\
\hline & 5 & 6.03 & 3.96 & 4.48 & 3.95 & - & 4.97 & 6.07 & 2.82 \\
\hline & 6 & 7.30 & 4.27 & 7.21 & 3.81 & 6.34 & 9.11 & 13.9 & 4.86 \\
\hline & 7 & 3.37 & 5.97 & 3.21 & 2.22 & 7.47 & 4.91 & 12.5 & 4.67 \\
\hline LLOQ & & 12.5 & 2.30 & 1.22 & 0.101 & 2.00 & 1.80 & 2.00 & 1.40 \\
\hline ULOQ & & 150 & 50.0 & 10.0 & 3.51 & 80.0 & 40.0 & 40.0 & 100 \\
\hline
\end{tabular}

VAL: valproic acid, AM: amikacin, GE: gentamicin, LIT: lithium, PHL: phenobarbital, PHO: phenytoin, THE: theophylline, VA: vancomycin. LLOQ and ULOQ are expressed in $\mathrm{mg} / \mathrm{L}$ except for lithium in $\mathrm{mmol} / \mathrm{L}$.

\section{Results and discussion}

The trueness of an analytical method describes the closeness of the determined value obtained by the method to the nominal concentration of the analyte expressed in terms of relative bias [10-14]. The trueness of the method is acceptable since the mean concentration is within $15 \%$ of the target values for the validation standards in the dosing range and within $20 \%$ for the validation standard with a target value closed to the LLOQ. Results for trueness are presented in table 2.

The precision was determined by measuring the coefficients of variation for repeatability (within day) and intermediate precision (between days) for each validation standard concentration. They did not exceed $15 \%$ in the dosing range and $20 \%$ for the validation concentration with a target value closed to the LLOQ. Results for precision are presented in table 2.
The uncertainty of measurement characterizes the dispersion of the values that could reasonably be attributed to the measurand [10-14]. The expanded uncertainty represents an interval around the results where the unknown true value can be observed with a confidence level of $95 \%$. The relative expanded uncertainties expressed in $\%$ are computed in table 2 .

The accuracy refers to the closeness of agreement between the experimental result and the target value. The accuracy takes into account the total error related to the test result (systematic and random errors). It is assessed from the accuracy profile which is obtained by linking the lower bounds and the upper bounds of the $\beta$-expectation tolerance intervals calculated at each validation standard concentration [11-14]. The accuracy profiles are illustrated in figure 1 . The intersections between the accuracy profile and the acceptance limits define the LLOQ which is the lowest concentration of analyte which can be quantify with an 


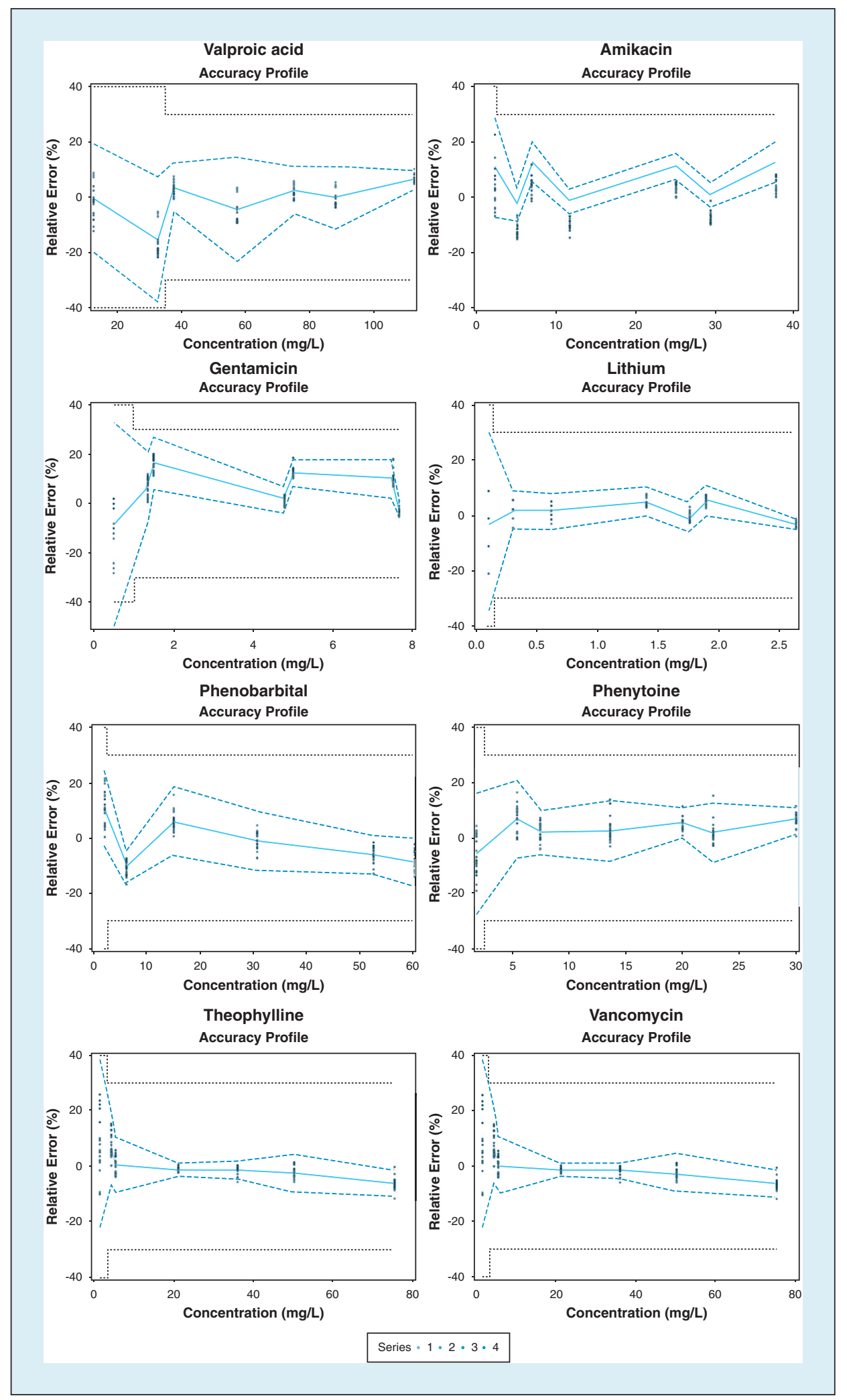

Figure 1. Accuracy profiles. 


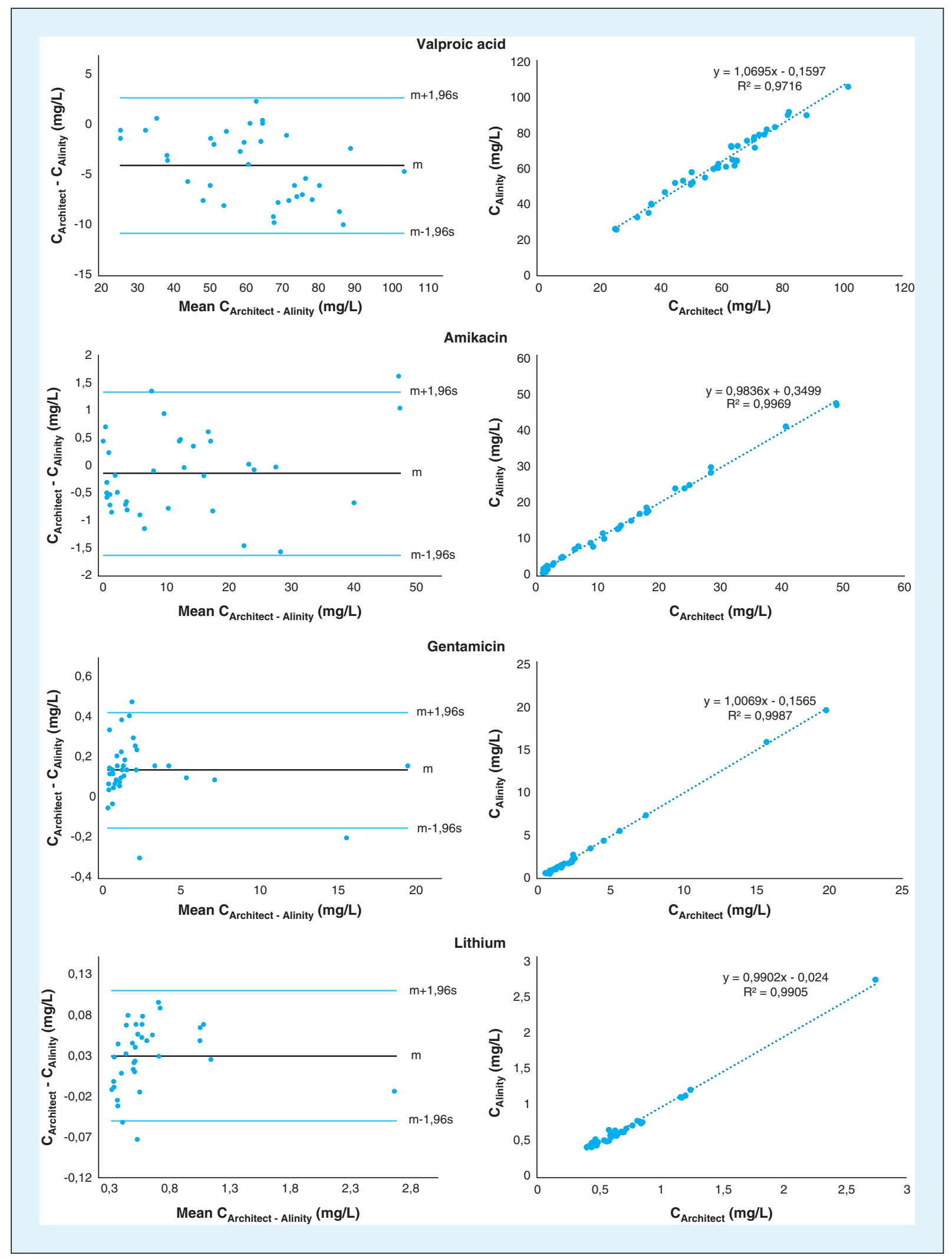

Figure 2. Method comparison between Architect ${ }^{\circledR}$ (reference) and Alinity ${ }^{\circledR}$ - Bland and Altman plots and linear regressions. 


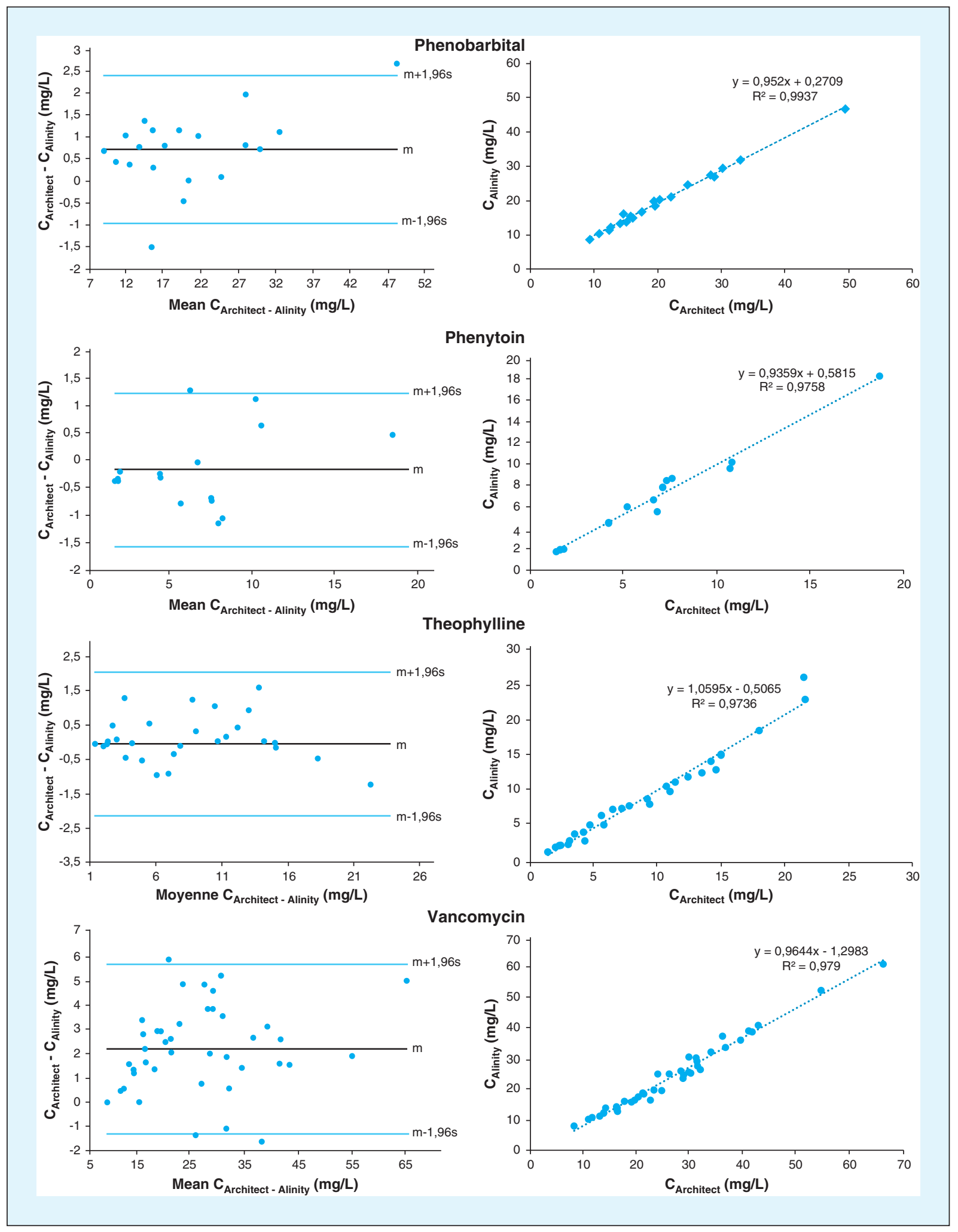

Figure 2. (Continued). 
acceptable trueness and precision. The upper limit of quantification (ULOQ) is the concentration of the last standard of calibration except for lithium which is optimized for target range between $04-1.0 \mathrm{mmol} / \mathrm{L}$. The LLOQ and ULOQ are presented in table 2 . The LLOQ for the quantitative determination of gentamicin is calculated at $1.22 \mathrm{mg} / \mathrm{L}$ in our validation study while Abbott determined it at $0.5 \mathrm{mg} / \mathrm{L}$. Abbott defines the LLOQ as the smallest concentration that can be determined with a maximal coefficient variation of $20 \%$ that is a less severe way of calculating LLOQ than ours. Having a LLOQ of $1.22 \mathrm{mg} / \mathrm{L}$ for gentamicin is not really challenging because trough therapeutic concentration commonly admitted and used in our laboratory is $<1 \mathrm{mg} / \mathrm{L}[17,18]$. All assays dilute linear as sample dilution does not affect the trueness and the precision (bias and CV lower than $15 \%)$ [10].

Analyte concentrations were not affected by hemolysis (highest hemoglobin concentration tested: $1070 \mathrm{mg} / \mathrm{dL}$ ) or by abnormal concentrations of bilirubine or triglycerides (respective highest concentrations tested of $0,965 \mathrm{~g} / \mathrm{L}$ and $2082 \mathrm{mg} / \mathrm{dL}$ ).

The results obtained for twenty to forty real patients taking the analytes as medication are comparable to those obtained with the instrument Architect ${ }^{\circledR}$ ci (Abbott). The Bland and Altman plots and the linear regressions are presented in figure 2. CMIA (valproic acid, gentamicin, phenobarbital, phenytoin, theophyllin and vancomycin), Petinia (amikacin) and colorimetric method (lithium) on Architect $^{\circledR}$ Ci4100/i1000 and Petinia (valproic acid, amikacin, gentamicin, phenobarbital, and vancomycin), immunoenzymatic method (phenytoin, theophyllin) and colorimetric method on Alinity ${ }^{\circledR}$ are equivalent analytical methods for therapeutic drug monitoring. These analytical techniques present a good correlation between them. Their concordance is demonstrated by the Bland-Altman method. The analyte stability at different storage conditions was previously studied on Architect ${ }^{\circledR}$ by Mistretta et al. [19].

\section{Conclusion}

The validation of the methods developed on the Abbott Instrument Alinity ${ }^{\circledR} \mathrm{c}$ for therapeutic drug monitoring of valproic acid, amikacin, gentamicin, lithium, phenobarbital, phenytoin, theophylline and vancomycin on the Abbot instrument Alinity ${ }^{\circledR} \mathrm{c}$ meets the requirements of EMA. The obtained results for the analytical validation confirm the Abbott internal validation except for gentamicin for which we determined the LLOQ at $1.22 \mathrm{mg} / \mathrm{L}$ while Abbott determined it at $0.5 \mathrm{mg} / \mathrm{L}$. Trueness was not studied by Abbott but our results showed that the systematic error is well controlled with acceptable relative bias of lower than $15 \%$. Results are not affected by hemolysis or abnormal concentrations of bilirubin or triglycerides. Concentrations obtained for real samples on the Alinity ${ }^{\circledR} \mathrm{c}$ are comparable to those obtained on the Architect $^{\circledR}$ ci.

Liens d'intérêts: This work was supported by the Abbott Diagnostics in Belgium [Educational grant 2019]. Les auteurs déclarent ne pas avoir de liens d'intérêts en rapport avec cet article.

\section{References}

1. Kang J-S, Lee M-H. Overview of therapeutic drug monitoring. Korean J Intern Med 2009;24(1) : 1-10.

2. Marquet P. Therapeutic monitoring: analytic, pharmacokinetic and clinical aspects. Acta Clin Belg 1999; 53(1) : 2-12.

3. Clarke W, Dasgupta A. Therapeutic drug monitoring: special populations, physiological conditions and pharmacogenomics, 1st ed. Cambridge : Elsevier, 2016.

4. Marquet P. Suivi thérapeutique pharmacologique : pour l'adaptation de posologie des médicaments, 1st ed. Paris : Elsevier, 2004.

5. Endo A, Nemoto A, Hanawa K, Maebayashi Y, Hasebe Y, Kabayashi $\mathrm{M}$, et al. Relationship between amikacin blood concentration and ototoxicity in low birth weight infants. J Infect Chemother 2019;25(1) : 17-21.

6. Wang L, Yuan Q, Tan M, Xie S, Wu J, Song X, et al. Evaluation of efficacy and nephrotoxicity during vancomycin therapy: a retrospective study in China. Exp Ther Med 2019; 17(3) :2389-96.

7. Khan A, Adil MS, Nematullah K, Ihtisham S, Aamer K, Aamir S. Causality assessment of adverse drug reactions in pulmonology department of a tertiary care hospital. J Basic Clin Pharm 2015; 6(3) : 84-8.

8. Patsalos PN, Spencer EP, Berry DJ. Therapeutic drug monitoring of antiepileptic drugs in epilepsy: a 2018 update. Ther Drug Monit $2018 ; 40(5): 526-48$.

9. Nederlof M, Heerdink ER, Egberts AC, Wilting I, Stoker LJ, Haekstra $\mathrm{R}$, et al. Monitoring of patients treated with lithium for bipolar disorder: an international survey. Int J Bipolar Disord 2018;6(1): 12.

10. European Medicines Agency, Guideline on bioanalytical method validation, 21 july 2011, https://www.ema.europa.eu/en/documents/ scientific-guideline/guideline-bioanalytical-method-validation_en.pdf, consulted the 19th march 2019.

11. Hubert $P$, Nguyen-Huu JJ, Boulanger $B$, Chapuzet E, Chiap P, Cohen $\mathrm{N}$, et al. Harmonization of strategies for the validation of quantitative analytical procedures. A SFSTP proposal - Part I. J Pharm Biomed Anal $2004 ; 36: 579-86$.

12. Hubert $P$, Nguyen-Huu JJ, Boulanger $B$, Chapuzet $E$, Chiap $P$, Cohen $\mathrm{N}$, et al. Harmonization of strategies for the validation of quantitative analytical procedures. A SFSTP proposal - Part II. J Pharm Biomed Anal $2007 ; 45: 70-81$

13. Hubert P, Nguyen-Huu JJ, Boulanger B, Chapuzet E, Cohen N, Compagnon PA, et al. Harmonization of strategies for the validation of quantitative analytical procedures. A SFSTP proposal - Part III. J Pharm Biomed Anal 2007 ; 45 : 82-96.

14. Rozet E, Ceccato A, Hubert C, Ziemons E, Oprean R, Rudaz S, et al. Analysis of recent pharmaceutical regulatory documents on analytical method validation. J Chromatogr A 2007; 1158: 111-25. 
15. Clinical and laboratory standards institute, Interference testing in clinical chemistry. Approved Guideline. Second ed. CLSI document EP7-A2 [ISBN 1-56238-584-4]. Clinical and Laboratory Standards Institute, 940 West Valley Road, Suite 1400, Wayne, Pennsylvania 19087-1898 USA, 2005.

16. Grenier B, Dubreuil M, Journois D. Comparaison de deux méthodes de mesure d'une même grandeur : méthode de Bland et Altman. Ann Fr Anesth Reanim $2000 ; 19(2): 128-35$.
17. Kovacevic T, Avram S, Milakovic D, Spiric N, Kovacevic P. Therapeutic monitoring of amikacin and gentamicin in critically and noncritically ill patients. J Basic Clin Pharm 2016; 7(3) : 65-9.

18. Dieusaert P. Guide pratique - Analyses médicales, 5th ed. Paris: Maloine, 2009.

19. Mistretta V, Denooz R, Charlier C. Temporal stability evaluation of drugs in plasma on primary sampling tube. Ther Drug Monit $2018 ; 40(5): 660-1$. 